\title{
Diet modification impact on ADHD outcome
}

\author{
Olweya Mohammed Abd El Baaki ${ }^{1}$, Enas Raafat Abd El Hamid², Safaa Taha Zaki², Amani Salah El Din Alwakkad³, \\ Rania Nabil Sabry ${ }^{2 *}$ and Eman Mohamed Elsheikh²
}

\begin{abstract}
Background: Attention-deficit hyperactivity disorder (ADHD) is one of the most common neurodevelopmental disorders, affects $5 \%$ of children worldwide and characterized by impaired inattention, hyperactivity and impulsivity. One of the risk factors that precipitate ADHD is food. Food affects behavior of children by different ways such as food allergy, food intolerance and gut-microbiota-brain axis. The study aimed to assess effect of diet modification on ADHD outcome and the role of food as a precipitating factor for ADHD symptomatology. The study included 47 children newly diagnosed with ADHD, not receiving medical or behavioral therapy, their ages ranged from 6 to 9 years and their intelligence quotient not below 70 with no associated comorbidities. All participants were subjected to Full history taking, clinical examination, anthropometric measurements, $24 \mathrm{~h}$ dietary recall. Dietary analysis and Conner's parent rating scale-revised short form (CPR-RS) were done before and after diet modification program for 5 weeks.

Results: There was improvement in ADHD symptoms as measured by CPR-RS after 5-weeks of diet modification program. Carbohydrate and protein intake decreased significantly after diet modification program. Energy intake did not show statistical difference while fat intake increased significantly after the diet program. Vitamin A, C, riboflavin, thiamin and iron intakes decreased significantly after diet program but were within the recommended dietary allowance.

Conclusion: Following the Diet modification program, ADHD symptoms were improved as documented by decrease in CPR scores. Diminished carbohydrate and protein intake in diet were positively associated with improvement of ADHD symptoms. Diet modification program succeeded in reducing obesity and then ADHD symptoms.
\end{abstract}

\section{Background}

Attention-deficit hyperactivity disorder (ADHD) is a neurodevelopmental psychiatric disorder that affects $5 \%$ of children worldwide and is characterized by excessive and impairing inattentive, hyperactive, and impulsive behavior (American Psychiatric Association (APA) 2013).

Genetic and environmental factors are involved in its etiology (Faraone and Larsson 2018). Pathophysiology of ADHD is unclear but research on children with ADHD has shown a general reduction in brain volume, with a proportionally greater reduction in the volume of the left-sided prefrontal cortex (Krain and Castellanos 2006).

At present, ADHD has been treated with psychoeducation, parent training, child behavioral interventions, and

\footnotetext{
*Correspondence: rania.n.sabry@gmail.com

${ }^{2}$ Department of Child Health, National Research Centre, Dokki, Egypt

Full list of author information is available at the end of the article
}

drugs such as stimulants (methylphenidate and amphetamines), noradrenergic treatment as atomoxetine and alpha-2A-adrenergic agonists as guanfacine and clonidine (Feldman et al. 2018).

One of the risk factors for ADHD that can be targeted for intervention is food (Thapar et al. 2013; Nigg and Holton 2014). Adverse physical reactions to foods as eczema, asthma, and gastro intestinal problems affect various organ systems and also affect the brain, resulting in adverse behavioral effects (Gomez-Pinella 2008). Colorings and preservatives have negative effects on the behavior of children with or without ADHD (McCann et al. 2007).

Food affects children's' behavior in different ways such as food allergy, food intolerance and gut-microbiota-brain axis (Petra et al. 2015). Food allergy causes increased levels of antigen-specific immunoglobulins and mast cell marker in the brain and these brain allergic
Springer Open

(c) The Author(s) 2020. Open Access This article is licensed under a Creative Commons Attribution 4.0 International License, which permits use, sharing, adaptation, distribution and reproduction in any medium or format, as long as you give appropriate credit to the original author(s) and the source, provide a link to the Creative Commons licence, and indicate if changes were made. The images or other third party material in this article are included in the article's Creative Commons licence, unless indicated otherwise in a credit line to the material. If material is not included in the article's Creative Commons licence and your intended use is not permitted by statutory regulation or exceeds the permitted use, you will need to obtain permission directly from the copyright holder. To view a copy of this licence, visit http://creativecommons.org/licenses/by/4.0/. 
responses are associated with behavioral impairments, including motor and learning deficits (Costa-Pinto et al. 2012).

Food intolerance is an adverse physiologic response to a food due to inherent properties of the food (i.e., toxic contaminant, pharmacologic active component) or characteristics of the host (i.e., metabolic disorders, idiosyncratic responses, psychological disorder). However, there is evidence that some children respond adversely to particular items of food with behavioral consequences and reactions that may occur for many reasons (Ortolani and Pastorello 2006).

There are many trials that investigated the effects of food on ADHD symptoms as colorings free diet, restricted elimination diet, gluten free diet and low sugar diet and there was a reported statistically significant and clinically relevant positive effect on ADHD (Pelsser et al. 2017).

\section{Methods}

This study included 47 children newly diagnosed with attention-deficit hyperactivity disorder (ADHD) recruited from the behavioral and psychiatric assessment unit of the National Research Center (NRC) and psychiatric clinics of Faculty of Postgraduate Childhood studies.

Patients were newly diagnosed with ADHD not receiving medications or behavioral therapy, aged 6-9 years and parents were motivated and capable to follow 5-weeks diet modification program.

Patients with the following criteria were excluded from our study:

1 Patients who are receiving pharmacological, behavioral therapy or already following any diet

2 Patients with family circumstances that were likely to prevent completion of the study and medical or metabolic conditions interfering with the diet modification such as metabolic disorders, diabetes mellitus.

3 Patients with intelligence quotient (IQ) below 70 and any psychiatric comorbidity other than oppositional defiant disorder or conduct disorder.

Each patient was subjected to history taking (complaint, developmental history, present history, family history and past history), examination (clinical, psychiatric and neurological) and anthropometric assessment (weight, height and Body Mass Index). Diagnosis of ADHD was made with diagnostic and statistical manual 5 (DSM-5). The DSM-5 diagnosis criteria of ADHD is "a persistent pattern of inattention and/or hyperactivity-impulsivity interfering with development and presented in two or more settings (e.g., at home, school, or work), and negatively impact on social, academic or occupational functioning." Symptoms should be present before age of 12 (American Psychiatric Association (APA) 2013).

IQ assessment was done with Wechsler intelligence scale for children (WISC-R) (عليكه, لويس كامل و إسماعيل, محمد 1993 (عماد الدين to exclude patients with IQ less than 70. Dietary history with $24 \mathrm{~h}$ recall and Diet analysis using the Egyptian food composition tables were done before and after diet modification program (National Nutrition Institute 2006).

Diet modification program was subdivided into two phases. Phase 1 (baseline period) in which patients were adhering to their normal diet and life for 2 weeks; no foods was eliminated. During the baseline, the program was explained to children and their parents, to know their ability to complete the study, written informed consent was obtained, parents were observing their children carefully, in order to assess and record the child's normal diet, behavior, symptoms and activities. Dietary history and analysis and Conner's parent rating scale-revised short form were done (البحيري, عبد الرقيب أحمد 2011'). Phase 2 (Diet modification) consists of health education and diet modification for 5 weeks.

The diet modification took into consideration the energy intake for each child according to age, sex and physical activity (United States Department of Agriculture and US Department of Health and Human Services 2010), macronutrient intake was distributed according to AMDR (Acceptable macronutrient distribution range) (CHO: 45-65\%; proteins: $10-35 \%$; fat $20-35 \%$ ) and then to number of exchanges according to food exchange lists (starch-vegetables-fruits-meat-fat-milk) (American Diabetes Association 2008). Meals were subdivided into 3 main meals and 2 snacks. The diet consisted of a limited number of hypoallergenic foods, like rice, potatoes, chicken, meat, a range of vegetables (lettuce, carrots, cabbage and cauliflower), a range of legumes (broad beans, kidney beans, lentils, peas and lupines) and a range of fruits (apples-pears-bananas-dates) or juices performed at home from allowed fruits with no added sugars and honey (Pelsser et al. 2011). Soya milk or rice milk were used instead of cow's milk. Foods containing gluten, egg, milk and dairy products were prohibited. Foods containing artificial food colors, preservatives and additives were excluded (Pelsser et al. 2009). Highly containing sulfites and salicylate foods were also avoided with stressing on drinking water (Nigg and Holton 2014).

Each patient was provided with diet sheets showing them foods they can eat, number of servings, how to prepare food with allowed foods and varieties of food they can have according to his/her energy intake. Records of the children behavior, symptoms and foods were filled by the parents or caregivers on weekly visits and daily 
Table 1 Anthropometric data of studied sample during baseline period and after diet modification

\begin{tabular}{|c|c|c|c|c|c|c|}
\hline & \multicolumn{2}{|l|}{ Weight (kg) } & \multicolumn{2}{|l|}{ Height (cm) } & \multicolumn{2}{|l|}{ BMI $\left(\mathrm{kg} / \mathrm{m}^{2}\right)$} \\
\hline & Mean \pm SD & Min.-max. & Mean \pm SD & Min.-max & Mean \pm SD & Min.-max \\
\hline During baseline period & $28.7 \pm 5.3$ & $19-41$ & $126 \pm 7$ & $111-139$ & $18.1 \pm 2.1$ & $14.5-21.5$ \\
\hline After diet modification & $28.2 \pm 5.3$ & $18-40$ & $126 \pm 7$ & $111-139$ & $17.7 \pm 2$ & $13.6-21$ \\
\hline$p$ value & $0.003^{\mathrm{a}}$ & & & & $0.000^{\mathrm{a}}$ & \\
\hline$t$ test & 3.146 & & & & 3.598 & \\
\hline
\end{tabular}

${ }^{a}$ Means highly significant, $t$ test: paired $t$ test

Table 2 BMI interpretation during baseline period and after diet modification program

\begin{tabular}{|c|c|c|c|c|}
\hline & During baseline period & After diet modification & $z$ & $p$ value \\
\hline Normal weight (5th-85th percentile) & 19 patients & 25 patients & -2.000 & $.046^{\mathrm{a}}$ \\
\hline Overweight (85th-95th percentile) & 19 patients & 15 patients & & \\
\hline Obese (> 95th percentile) & 9 patients & 7 patients & & \\
\hline
\end{tabular}

$Z$ Wilcoxon rank test

a Significant

telephone follow-up. Dietary questionnaires were used to survey information on the adherence and challenges to the program in each visit. There was focusing on foods rich in calcium and vitamin $\mathrm{D}$ as legumes, fish and dark green vegetables to compensate the lack of milk, dairy products and eggs.

\section{Statistical analysis}

Data entry was carried out on excel sheet and analysis was done using SPSS software program version 22 (SSPS Inc., Pennsylvania, USA). Mean \pm SD was used to present quantitative data. $t$ test was done for comparison between two means. Pearson's correlation analysis was performed to estimate the association between variables. $p$ value was considered statistically significant when $p$ was $<0.05$.

\section{Results}

There was statistically significant decrease in weight of patients after diet modification program with statistically significant decrease in BMI as shown in Table 1.

As shown in Table 2, there was a statistically significant decrease in number of obese and overweight patients after diet modification program.

Eighteen patients were predominantly hyperactiveimpulsive, 18 patients were with combined presentation and 11 patients were predominantly inattentive as presented in Fig. 1.

The energy intake of the studied patients after diet modification program decreased but the decrement was not statistically significant from intake during baseline.

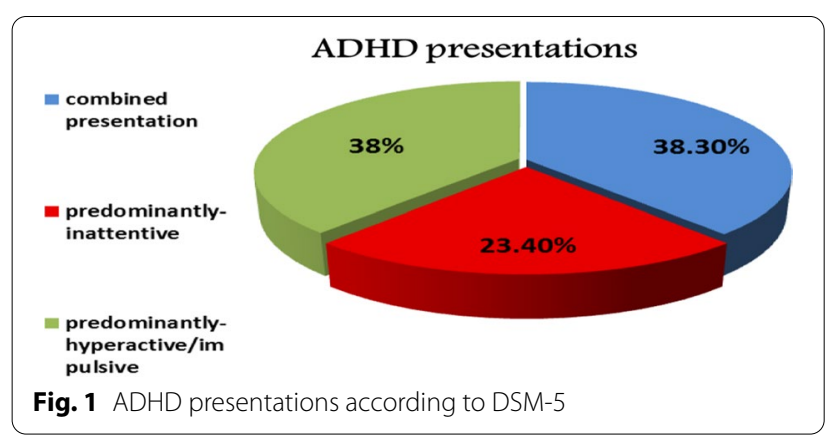

The carbohydrate and protein intakes after diet modification showed statistically significant decrement from their intakes during baseline period. Fat intake after diet modification program increased statistically significantly than its intake during baseline. Vitamin A and C intakes showed statistically significant decrement after diet modification as shown in Table 3.

There is significant decrease in CPR scales (hyperactivity index, impulsivity/hyperactivity and learning problems) after diet modification program, also there is statistical significant difference in hyperactivity index scores of CPR done during baseline between normal weight versus obese cases and between overweight versus obese while there was no statistical significant difference between normal weights versus overweight children. There were no statistical significant differences in impulsive/hyperactivity scores and learning problem scores between different BMI categories as shown in Tables 4 and 5 and Fig. 2. 
Table 3 Comparison of macronutrients and micronutrients intakes in the studied children during baseline period and after diet modification

\begin{tabular}{|c|c|c|c|c|c|c|}
\hline & \multicolumn{2}{|l|}{ Energy (calories) } & \multicolumn{2}{|l|}{ Carbohydrate (g) } & \multicolumn{2}{|l|}{ Protein $(\mathbf{g})$} \\
\hline & During baseline & After diet program & During baseline & After diet program & During baseline & After diet program \\
\hline Mean $\pm S D$ & $1726.33 \pm 309.3$ & $1649.47 \pm 218.76$ & $206.9 \pm 53.3$ & $174.6 \pm 24.3$ & $60 \pm 21.3$ & $39.2 \pm 7.8$ \\
\hline Min.-max. & $1200-2965$ & $1032-2060$ & $126.6-408$ & $138-230$ & $14-114$ & $26-56$ \\
\hline$t$ test & 1.79 & & 4.1 & & 6.412 & \\
\hline \multirow[t]{3}{*}{$p$ value } & $.08(N S)$ & & $.000(\mathrm{HS})$ & & .000 (HS) & \\
\hline & \multicolumn{2}{|l|}{ Fat (g) } & \multicolumn{2}{|l|}{ Vitamin A $(\mu \mathrm{g})$} & \multicolumn{2}{|l|}{ Vitamin C (mg) } \\
\hline & During baseline & After diet program & During baseline & After diet program & During baseline & After diet program \\
\hline Mean \pm SD & $73 \pm 21.6$ & $84.9 \pm 12.5$ & $721.1 \pm 521.43$ & $551.8 \pm 191.78$ & $56.34 \pm 40.43$ & $42.61 \pm 16.2$ \\
\hline Min.-max. & $36.5-124$ & $65-120$ & 170-3017 & 274-990 & $5.7-211$ & $25-78$ \\
\hline$t$ test & -2.839 & & 3.043 & & 2.772 & \\
\hline$p$ value & $.007(\mathrm{HS})$ & & $.004(\mathrm{HS})$ & & $.008(\mathrm{HS})$ & \\
\hline
\end{tabular}

Table 4 CPR scores during baseline and after diet modification

\begin{tabular}{lcclll}
\hline CPR-RS subscales & Mean \pm SD & Min & Max & $\boldsymbol{p}$ value & $\boldsymbol{Z}$ value \\
\hline Hyperactivity index & & & & & \\
During baseline & $69.38 \pm 14.1953$ & 95 & $.000^{\mathrm{a}}$ & -4.650 \\
$\begin{array}{l}\text { After diet program } \\
\text { Impulsive hyperactive }\end{array}$ & $64 \pm 11.99$ & 52 & 92 & $\mathrm{HS}$ & \\
$\begin{array}{l}\text { During baseline } \\
\text { After diet program }\end{array}$ & $65.94 \pm 7.3650$ & 77 & $.000^{\mathrm{a}}$ & -4.340 \\
Learning & $64.31 \pm 6.9349$ & 74 & $\mathrm{HS}$ & \\
$\begin{array}{l}\text { During baseline } \\
\text { After diet program }\end{array}$ & $71.85 \pm 12.5853$ & 96 & $.000^{\mathrm{a}}$ & -3.517 \\
\hline
\end{tabular}

CPR-RS Conner's parent rating scale-revised short form, HS highly significant, NS not significant

a means highly significant

There is negative correlation between hyperactivity index of CPR scale and vitamin A intake during baseline period as shown in Table 6 and Fig. 3.

Table 7 shows significant positive correlation existed between carbohydrate intake and hyperactivity index, and between carbohydrate intake and learning problem scores of Conner's parent rating (CPR).

\section{Discussion}

Attention-Deficit Hyperactivity Disorder (ADHD) is a neurobehavioral disorder, and one of the most common neurodevelopmental disorders in childhood that is characterized by developmentally inappropriate behaviors of inattention, and/or impulsivity and hyperactivity. These behavioral manifestations contribute to diminish academic, occupational and social functioning (American Psychiatric Association (APA) 2013).
In this study, $40.5 \%$ of children were normal weight, $40.5 \%$ were overweight and $19 \%$ were obese before diet modification ( $1 / 2$ of patients were overweight and obese) going with the systematic review and metaanalysis by Cortese and Vincenzi (2011) who found that the prevalence of ADHD in clinical samples of patients seeking treatment for their obesity is higher than that in the general population. Also, Cortese and Tessari (2017) showed a significant association between ADHD and obesity with a possible explanation that obesity and factors associated with it (such as sleep-disordered breathing and deficits in arousal/alertness) manifest as ADHD-like symptoms or that ADHD and obesity share common genetics and neurobiological dysfunctions, involving the dopaminergic system.

After diet modification program, 53\% became normal weight, $32 \%$ overweight and $7 \%$ obese with significant reduction in weight and body mass index (BMI) implicating effectiveness of diet modification intervention in weight reduction.

The obese patients had higher scores of hyperactivity index of Conner's parent rating scale (CPR-RS) at baseline period as shown by ANOVA test $(F=6.8$ and sig.003). A study of Hamid et al. (2015) on Egyptian children found that childhood obesity was associated with serum levels of monocyte chemoattractant protein-1 (MCP-1) and interlukin-6 (IL-6) predisposing to systemic inflammation including neuroinflammation causing foggy brain and development of neuropsychiatric disorders and this is also reported by a study performed by Theoharides et al. (2015).

In comparison to Tong et al. (2017) who concluded that ADHD contributed to emotional eating and 
Table 5 Comparison of CPR scores between patients of different BMI categories during baseline period

\begin{tabular}{|c|c|c|c|c|c|c|}
\hline \multirow[t]{2}{*}{ CPR-RS subscales during baseline } & \multirow{2}{*}{$\begin{array}{l}\text { Normal weight } \\
n=19\end{array}$} & \multirow{2}{*}{$\begin{array}{l}\text { Overweight } \\
n=19\end{array}$} & \multirow{2}{*}{$\begin{array}{l}\text { Obese } \\
n=9\end{array}$} & \multicolumn{3}{|c|}{ One way ANOVA } \\
\hline & & & & \multicolumn{2}{|l|}{$F$} & $p$ value \\
\hline Hyperactivity index (mean \pm SD) & $66.84 \pm 13.4$ & $65.32 \pm 12.98$ & $83.38 \pm 14.2$ & \multicolumn{2}{|l|}{6.809} & $\begin{array}{l}.003^{\mathrm{a}} \\
\mathrm{HS}\end{array}$ \\
\hline Impulsivity/hyperactivity (mean \pm SD) & $65.53 \pm 7.1$ & $65.32 \pm 8.56$ & $68.11 \pm 5.28$ & \multicolumn{2}{|l|}{.479} & $\begin{array}{l}.623 \\
\text { NS }\end{array}$ \\
\hline Learning problems (mean \pm SD) & $72.32 \pm 14.44$ & $70.1 \pm 10.67$ & $74.67 \pm 12.96$ & \multicolumn{2}{|l|}{.421} & $\begin{array}{l}.659 \\
\text { NS }\end{array}$ \\
\hline \multicolumn{7}{|c|}{ Comparison (Post hoc analysis using LSD) } \\
\hline & \multicolumn{2}{|c|}{$\begin{array}{l}\text { Normal weight versus overweight } p \\
\text { value }\end{array}$} & $\begin{array}{l}\text { Normal weight versus obese } p \\
\text { value }\end{array}$ & \multicolumn{3}{|c|}{$\begin{array}{l}\text { Overweight } \\
\text { versus obese } p \\
\text { value }\end{array}$} \\
\hline Hyperacti + vity index scores & $.712(\mathrm{NS})$ & \multicolumn{2}{|r|}{$.002(\mathrm{HS})$} & \multicolumn{3}{|c|}{$.001(H S)$} \\
\hline Impulsive/hyperactivity scores & $.931(\mathrm{NS})$ & \multicolumn{2}{|r|}{$.396(N S)$} & \multicolumn{3}{|c|}{$.359(N S)$} \\
\hline Learning problem scores & $.587(\mathrm{NS})$ & \multicolumn{2}{|r|}{$.651(N S)$} & \multicolumn{3}{|c|}{$.376(N S)$} \\
\hline
\end{tabular}

NS non-significant $(p>.05)$, HS highly significant $(p<.01)$

a Highly significant $(p<.01)$

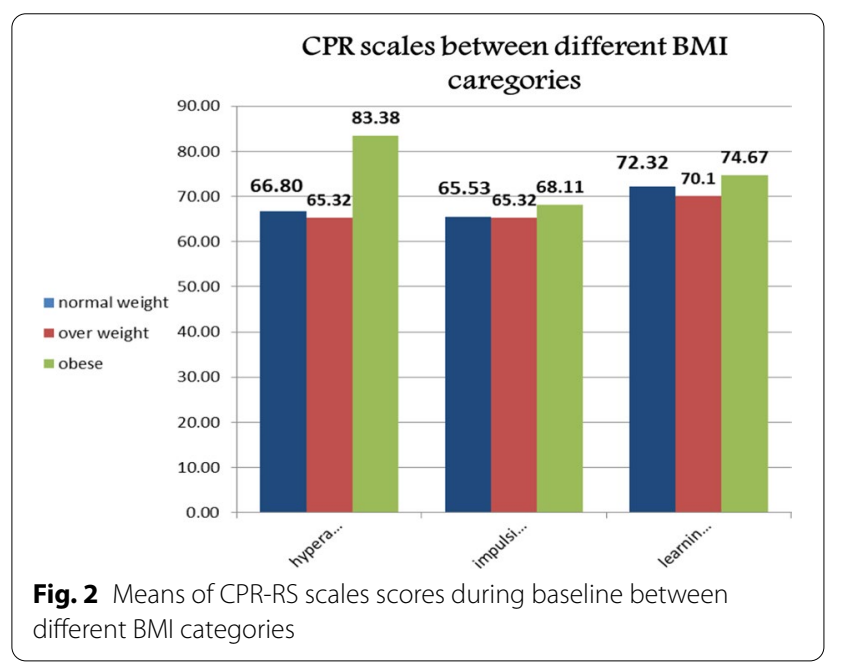

Table 6 Correlation between dietary vitamin A intake and CPR-RS subscales scores during baseline period

\begin{tabular}{llllll}
\hline $\begin{array}{l}\text { CPR-RS subscales } \\
\text { scores during baseline }\end{array}$ & \multicolumn{2}{l}{$\begin{array}{l}\text { Vitamin A intake } \\
\text { during baseline }\end{array}$} & & \multicolumn{2}{l}{$\begin{array}{l}\text { Vitamin C intake } \\
\text { during baseline }\end{array}$} \\
\cline { 2 - 3 } & $\boldsymbol{R}$ & $\boldsymbol{p}$ value & & $\boldsymbol{R}$ & $\boldsymbol{p}$ value \\
\hline Hyperactivity index & $-.291^{\mathrm{a}}$ & .047 & & .031 & .834 \\
Impulsivity/hyper & -.070 & .642 & & .026 & .862 \\
Learning prob & .055 & .712 & & .221 & .136 \\
\hline
\end{tabular}

a means significant

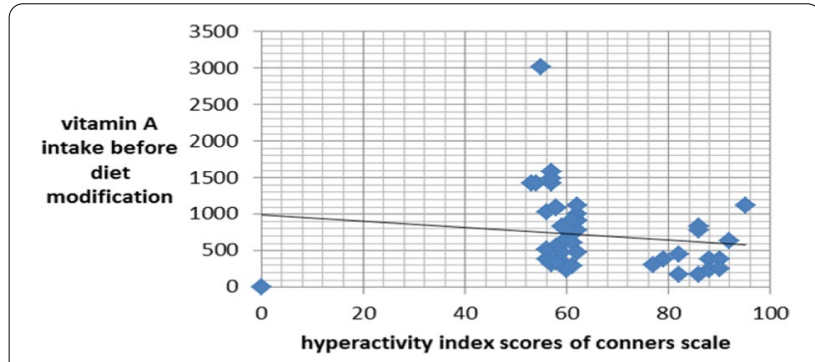

Fig. 3 Correlation between hyperactivity index scores and dietary vitamin A intake during baseline period

Table 7 Correlation of CPR-RS subscales scores and carbohydrate intake during baseline period

CPR-RS subscales during baseline Carbohydrate intake during baseline

\begin{tabular}{lll}
\cline { 2 - 3 } & $\boldsymbol{R}$ & $\boldsymbol{p}$ value \\
\hline Hyperactivity index & $.304^{\mathrm{a}}$ & .038 \\
Impulsivity/hyperactivity scores & .159 & .286 \\
Learning problems & $.295^{\mathrm{a}}$ & .044 \\
\hline
\end{tabular}

a means significant

bulimia nervosa but there was no significant relationship between ADHD and BMI.

The present study showed positive effect of the diet modification on ADHD outcome, it was noted that there was a decrease in the behavioral disturbance as assessed by CPR-RS. All subscales of CPR-RS decreased statistically significantly after diet modification. There 
was statistically significant decrease in hyperactivity index scores, hyperactivity/impulsivity scores and learning problems after diet program $(66.21 \pm 12.95$ vs. $64.06 \pm 11.98), \quad(65.93 \pm 7.36$ vs. $64.31 \pm 6.93)$, (71.85 \pm 12.58 vs. $70.14 \pm 11.82)$.

There is notable similarities between these findings and another study performed by Pelsser et al. (2011) in which children aged 4-8 year diagnosed with ADHD were randomly assigned to 5 weeks of a restricted elimination diet (diet group) or to instructions for a healthy diet (control group), the difference between the diet group and the control group in the mean of abbreviated Conner's scale (ACS) score at end of the 5 weeks was significant $(p<0.0001)$ showing effectiveness of this diet in improving symptomatology of ADHD.

In line with this study, Benton (2007) and Nigg and Holton (2014) reported that few foods diet (FFD) which consists of "lamb, chicken, potatoes, rice, banana, apple and cabbage; foods for a period of one week has a positive effect in case of comorbid food allergy with ADHD. That was in accordance with Beela abd Raji (2017) who detected improvement in ADHD symptoms after reduction in carbohydrate intake in group of Korean children aged from (4-12) years in comparison to control group who are diagnosed with ADHD but did not follow carbohydrate restriction. Also, Lien et al. (2006) found that the odds ratios for mental difficulties, hyperactivity and conduct problems were highest in those reporting the greatest levels of simple sugar consumption.

In this study, the energy intake after diet modification decreased with no significant difference from energy intake before diet modification ( $p$ value .08). But, there was statistically significant reduction in carbohydrate intake of patients after diet modification $(t=4.1$, $p=.000$ ).

Significant positive correlation existed between both carbohydrate intake of the patients during baseline and hyperactivity index scores of CPR scale and learning problem scores of CPR scale during baseline $(r=0.3$ and 0.29 , respectively, and $p$ value $=.03$ and.04, respectively). This can be explained by the intake of foods high on the glycemic index lead to oscillating blood sugar levels that are reflected in behavior, as blood sugar goes up, and then crashes, triggering the release of stress hormones like adrenaline and in the same time homeostasis of blood and cellular glucose is very important for the functioning of the central nervous system (CNS), that fits the same research by Cryer (2008) and Akaltun et al. (2019).

While another study of Kim and Chang (2011) which was performed on Korean fifth grade children found no relationship between consumption of carbohydrates and hyperactivity behavior.
In this study, any food containing artificial colorings, additives, preservatives or gluten were excluded and eliminated from the diet modification program and that was associated with improvement in behavior as measured by CPR going with many studies evaluated the effect of food color restriction as Schab and Trinh (2004), Nigg et al. (2012), Sonuga-Barke et al. (2013) and Stevenson et al. (2014) who concluded that there was reliable effect when synthetic food colors were restricted.

Also, Bateman et al. (2004) found that children when subjected to a diet eliminating artificial colorings and benzoate preservatives for 1 week showed significant reduction in hyperactive behavior; in the subsequent 3 weeks and when they received random order periods of dietary challenge with a drink containing artificial colorings ( $20 \mathrm{mg}$ daily) and sodium benzoate, they showed greater increase in hyperactive behavior.

This could be explained by that sulfotransferase inhibitors found in artificial food colors lead to increment of catechol amines, with negative effects on proper functioning of the prefrontal cortex where ADHD behavior can arise as mentioned by Eagle (2014) and Nigg and Holton (2014) or due to erythrosine-induced inhibition of serotonergic activity and corticosterone effects of erythrosine which could affect brain function without crossing the blood-brain barrier as explained with Dalal and Podar (2010).

In current study, the protein intake of patients decreased significantly after diet modification $(p=0.000$ and $t$ test $=6.41$ ), As with Kim and Chang (2011), who found that at risk children for ADHD had higher protein intakes than non-risk group. Also Niederhofer (2011) found that gluten free diet improved ADHD symptoms.

Czaja-Bulsa (2015) explained that gluten-related disorders (celiac disease, gluten allergy, non-celiac gluten sensitivity) are associated with behavioral disorders as disturbance in attention and hyperactivity. Also, Zelnik et al. (2004) found that $20.7 \%$ of celiac disease (CD) patients had evidence of learning disability/ADHD compared with only $10.5 \%$ of control patients which necessitate further checking for celiac disease in the ADHD symptom checklist.

The elimination of milk, eggs and dairy products in this study come in line with some studies as Elder et al. (2006) and Taylor et al. (2018) which showed that a diet free of cow milk, egg and related by-products, and several histamine-releasers foods, produced a notable improvement of both attention and hyperkinesia in $79 \%$ of cases.

Yaghmaie et al. (2013) reported that allergic response to milk, eggs and dairy products was paralleled by increasing prevalence of mental health problems such as attention-deficit/hyperactivity disorder (ADHD) and depression. On the contrary, a study of Park et al. (2012) 
found that high intake of dairy products is associated with less learning, attention, and behavioral problems.

In current study, fat intake increased after diet modification, the mean of fat intake was $73 \pm 21.6 \mathrm{~g}$ while after diet modification, it is $84.9 \pm 12.5 \mathrm{~g}$ with statistically significant increment $(p=0.007)$. Maalouf et al. (2009) and Bostock et al. (2017) showed that calorie restriction and high fat intake diet possess broad therapeutic potential in various neurological diseases.

In this study, mean dietary intake of vitamin A and vitamin $C$ decreased statistically significantly after diet modification and there was significant negative correlation between vitamin A intakes during baseline and hyperactivity index scores of CPR scale during baseline (Pearson correlation -0.318 and significance 0.03 ).

In the same context are Kim and Chang (2011) who reported that vitamin $\mathrm{A}$ and $\mathrm{C}$ intakes in risk group of Korean children did not reach the daily recommended level and Mikirova (2015) who found that subjects with ADHD were deficient in nutrients such as zinc, vitamin B3, magnesium, and vitamin C.

Annelies et al. (2018) showed that vitamin A and C have some antioxidant and neuroprotective effect. That can be explained by that vitamin $C$ is critical component of the antioxidant system. Oxidative stress caused by chronic inflammation, heavy metal or other environmental exposures, and hyperexcited neurons place heavy demands on the brain's antioxidant system as fit with Lopresti (2015).

\section{Conclusion}

Diet modification program in the form of adjustment of energy and macronutrient intake, with exclusion of food additives, gluten, milk and dairy products, eggs, and highly containing salicylate and sulfite foods and following health education tips (regular sleep, limit TV time) improved symptoms and behavior of ADHD patients as documented by decrease in scores of Conner's parent rating.

Obesity has a great role in influencing hyperactivity, impulsivity and learning problems in ADHD patients. Diet modification program succeeded in reducing obesity and then ADHD symptoms.

Restricted carbohydrate intake in diet is being highly effective on decreasing hyperactivity and learning problems in ADHD patients. Fat intake showed significant increase after following diet modification program which maybe one of the reasons of decreased hyperactivity. Finally, this study concludes the great impact of diet modification on diminishing symptoms of ADHD not only by the direct effect on hyperactivity and learning problems but also by decreasing BMI which in turn improve symptoms in ADHD patients.

\section{Abbreviations}

ADHD: Attention-deficit hyperactivity disorder; GMB: Gut-microbiota-brain axis; IQ: Intelligence quotient; CPR-RS: Conner's parent rating scale-revised short form; RDA: Recommended dietary allowance; NRC: National Research Center; BMI: Body Mass Index; DSM-5: Diagnostic and statistical manual of mental disorders-5; WISC-R: Wechsler intelligence scale for children; ADMR: Acceptable macronutrient distribution range; CNS: Central nervous system.

\section{Acknowledgements}

We would like to express our deepest gratitude to all children participated in this study and their parents for their cooperation till achieving our target. Also, would like to thank all authors for their help and cooperation. Finally, we would like to thank all staff members of Child Health Department, NRC and Department Of Medical Studies, Faculty of Postgraduate Childhood Studies.

\section{Authors' contributions}

OA. was the professor of psychiatry who examined the children for the first time and diagnosed them. EA. made the study design and revised the work. SZ. was the nutrition consultant who put the diet program for the children. AA. revised the work and made data analysis. RS. wrote the research and is the corresponding author. EE. dealt with the children and their parents and made follow-up for diet restriction. All authors have read and approved the final manuscript.

\section{Funding}

Not applicable.

\section{Availability of data and materials}

Data used during the current study are available from the corresponding author on reasonable request.

\section{Ethical approval and consent to participate}

This research was approved by the ethical committee of NRC with approval number 13066 and written consents were taken from the parents of each participant telling their approval for participating their children in the research.

Consent for publication

All authors were informed about publication and they agreed.

\section{Competing interests}

The authors declare that they have no competing interests.

\section{Author details}

${ }^{1}$ Department of Medical Studies, Faculty of Postgraduate Childhood Studies, Ain shams university, Egypt. ${ }^{2}$ Department of Child Health, National Research Centre, Dokki, Egypt. ${ }^{3}$ Department of Physiology, National Research Centre, Dokki, Egypt.

Received: 2 July 2020 Accepted: 7 December 2020

Published online: 09 January 2021

\section{References}

Akaltun I, Tayfun KA, Cayir A, Ayaydin H (2019) Is There a Relation between type 1 diabetes mellitus and ADHD and severity of ADHD in children and adolescents? A case-control study. Osmangazi Tıp Dergisi 42:165-172

American Diabetes Association (2008) Nutrition recommendations and interventions for diabetes: a position statement of the American Diabetes Association. Diabetes Care 31(Supplement 1):S61-S78

American Psychiatric Association (APA) (2013) Diagnostic and statistical manual of mental disorders (DSM-5). American Psychiatric Pub, Washington, DC

Annelies V, Harry R, Ines W, Annelies B, Tess DB (2018) Evaluation of biomarkers of oxidative stress in attention-deficit/hyperactivity disorder (ADHD). J MolBiomarkDiagn 9(390):2 
Bateman B, Warner JO, Hutchinson E, Dean T, Rowlandson P, Gant C, Grundy J, Fitzgerald C, Stevenson J (2004) The effects of a double blind, placebo controlled, artificial food colourings and benzoate preservative challenge on hyperactivity in a general population sample of preschool children. Arch Dis Child 89(6):506-511

Beela GK, Raji VR (2017) Impact of diet intervention on the attention deficit hyperactivity disorder (ADHD) symptomatology in school going children. J Psychol 8(2):77-82

Benton D (2007) The impact of diet on anti-social, violent and criminal behaviour. NeurosciBiobehav Rev 31(5):752-774

Bostock E, Kirkby KC, Taylor BV (2017) The current status of the ketogenic diet in psychiatry. Front Psychiatry 8:43

Cortese S, Tessari L (2017) Attention-deficit/hyperactivity disorder (ADHD) and obesity: update 2016. Curr Psychiatry Rep 19(1):4

Cortese S, Vincenzi B (2011) Obesity and ADHD: clinical and neurobiological implications. In: Stanford C, Tannock R (eds) Behavioral neuroscience of attention deficit hyperactivity disorder and its treatment. Springer, Berlin, pp 199-218

Costa-Pinto FA, Basso AS (2012) Neural and behavioral correlates of food allergy. In: Bienenstock J (ed) Allergy and the Nervous System, vol 98. Karger Publishers, Basel, pp 222-239

Cryer PE (2008) The barrier of hypoglycemia in diabetes. Diabetes 57(12):3169-3176

Czaja-Bulsa G (2015) Non coeliac gluten sensitivity—a new disease with gluten intolerance. ClinNutr 34(2):189-194

Dalal A, Poddar MK (2010) Involvement of high plasma corticosterone status and activation of brain regional serotonin metabolism in long-term erythrosineinduced rearing motor hyper activity in young adult male rats. ToxicolMech Methods 20(6):287-297

Eagle K (2014) ADHD impacted by sulfotransferase (SULT1A) inhibition from artificial food colors and plant-based foods. PhysiolBehav 135:174-179

El Hamid ERA, Abdel-Shaheed AA, Sabry RN, Youness ER, Shady MMA, Megawer AS, Mohamed NA (2015) Serum levels of monocyte chemoattractant protein-1, interlukin-6, and paraoxonase-1 in childhood obesity. J Arab Soc Med Res 10(1):27

Elder JH, Shankar M, Shuster J, Theriaque D, Burns S, Sherrill L (2006) The glutenfree, casein-free diet in autism: results of a preliminary double blind clinical trial. J Autism Dev Disord 36(3):413-420

Faraone SV, Larsson H (2018) Genetics of attention deficit hyperactivity disorder. Mol Psychiatry 24:562-575

Feldman ME, Charach A, Bélanger SA (2018) ADHD in children and youth: part 2-treatment. Paediatr Child Health 23(7):462-472

Gomez-Pinella F (2008) Brain foods: the effects of nutrients on brain function. Nat Rev Neurosci 9:568-578

Kim Y, Chang H (2011) Correlation between attention deficit hyperactivity disorder and sugar consumption, quality of diet, and dietary behavior in school children. Nutr Res Pract 5(3):236-245

Krain AL, Castellanos FX (2006) Brain development and ADHD. ClinPsychol Rev 26(4):433-444

Lien L, Lien N, Heyerdahl S, Thoresen M, Bjertness E (2006) Consumption of soft drinks and hyperactivity, mental distress, and conduct problems among adolescents in Oslo, Norway. Am J Public Health 96(10):1815-1820

Lopresti L (2015) Oxidative and nitrosative stress in ADHD: possible causes and the potential of antioxidant-targeted therapies. Attent Deficit HyperactDisord 7(4):237-247

Maalouf M, Rho JM, Mattson MP (2009) Theneuroprotective properties of calorie restriction, the ketogenic diet, and ketone bodies. Brain Res Rev 59(2):293-315

McCann D, Barrett A, Cooper A, Crumpler D, Dalen L, Grimshaw K, Kitchin E, Lok K, Porteous L, Prince E, Sonuga-Barke E (2007) Food additives and hyperactive behaviour in 3-year-old and 8/9-year-old children in the community: a randomised, double-blinded, placebo-controlled trial. The Lancet 370(9598):1560-1567

Mikirova N (2015) Clinical test of pyrroles: usefulness and association with other biochemical markers. Clin Med Rev Case Rep Clin Study 4:4-11

National Nutrition Institute (2006) Food composition tables. Ministry of Health and Population, Cairo
Niederhofer $\mathrm{H}$ (2011) Association of attention-deficit/hyperactivity disorder and celiac disease: a brief report. Prim Care Companion CNS Disord 13(3):1-3

Nigg JT, Holton K (2014) Restriction and elimination diets in ADHD treatment. Child AdolescPsychiatrClin 23(4):937-953

Nigg JT, Lewis K, Edinger T, Falk M (2012) Meta-analysis of attention-deficit/ hyperactivity disorder or attention-deficit/hyperactivity disorder symptoms, restriction diet, and synthetic food color additives. J Am Acad Child Adolesc Psychiatry 51(1):86-97.e8

Ortolani C, Pastorello EA (2006) Food allergies and food intolerances. Best Pract Res ClinGastroenterol 20(3):467-483

Park S, Cho SC, Hong YC, Oh SY, Kim JW, Shin MS, Kim BN, Yoo HJ, Cho IH, Bhang SY (2012) Association between dietary behaviors and attention-deficit/ hyperactivity disorder and learning disabilities in school-aged children. Psychiatry Res 198(3):468-476

Pelsser LM, Frankena K, Toorman J, Savelkoul HF, Pereira RR, Buitelaar JK (2009) A randomised controlled trial into the effects of food on ADHD. Eur Child Adolesc Psychiatry 18(1):12-19

Pelsser LM, Frankena K, Toorman J, Savelkoul HF, Dubois AE, Pereira RR, Haagen TA, Rommelse NN, Buitelaar JK (2011) Effects of a restricted elimination diet on the behaviour of children with attention-deficit hyperactivity disorder (INCA study): a randomised controlled trial. The Lancet 377(9764):494-503

Pelsser LM, Frankena K, Toorman J, Pereira RR (2017) Diet and ADHD, reviewing the evidence: a systematic review of meta-analyses of double-blind placebo-controlled trials evaluating the efficacy of diet interventions on the behavior of children with ADHD. PLoS ONE 12(1):e0169277

Petra Al, Panagiotidou S, Hatziagelaki E, Stewart JM, Conti P, Theoharides TC (2015) Gut-microbiota-brain axis and its effect on neuropsychiatric disorders with suspected immune dysregulation. ClinTher 37(5):984-995

Schab DW, Trinh NT (2004) Do artificial food colors promote hyperactivity in children with hyperactive syndromes? a meta-analysis of double-blind placebo-controlled trials. J Dev BehavPediatr 25(6):423-434

Sonuga-Barke EJS, Brandeis D, Cortese S et al (2013) Nonpharmacological interventions for ADHD: systematic review and meta-analyses of randomized controlled trials of dietary and psychological treatments. Am J Psychiatry 170:275-289

Stevenson J, Buitelaar J, Cortese S, Ferrin M, Konofal E, Lecendreux M, Simonoff E, Wong IC, Sonuga-Barke E, European ADHD Guidelines Group (2014) Research review: the role of diet in the treatment of attention-deficit/ hyperactivity disorder - an appraisal of the evidence on efficacy and recommendations on the design of future studies. J Child Psychol Psychiatry 55(5):416-427

Taylor MR, Chuang C, Carrasco KD, Nagatomo S, Rucklidge JJ (2018) Dietary and micronutrient treatments for children with neurodevelopment disorders. Curr Dev Disord Rep 5(4):243-252

Thapar A, Cooper M, Eyre O, Langley K (2013) Practitioner review: what have we learnt about the causes of ADHD? J Child Psychol Psychiatry 54(1):3-16

Theoharides TC, Stewart JM, Hatziagelaki E (2015) Brain "fog", inflammation and obesity: key aspects of neuropsychiatric disorders improved by luteolin. Front Neurosci 9:225

Tong L, Shi H, Li X (2017) Associations among ADHD, abnormal eating and overweight in a non-clinical sample of Asian children. Sci Rep 7(1):2844

United States Department of Agriculture and US Department of Health and Human Services (2010) Dietary guidelines for Americans, 2010. US government printing office, January 2011

Yaghmaie P, Koudelka CW, Simpson EL (2013) Mental health comorbidity in patients with atopic dermatitis. J Allergy Clinlmmunol 131(2):428-433

Zelnik N, Pacht A, Obeid R, Lerner A (2004) Range of neurologic disorders in patients with celiac disease. Pediatrics 113(6):1672-1676

البحيري, عبد الرقيب أحمد (2011). مقياس كونورز لتقدير الو الدين لسلوك الأطفال و المر اهقين. مكتبة

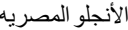

مليكه, لويس كامل و إسماعيل, محمد عماد الدين (1993). مقياس ويكسلر لذكاء الأطفال. مكتبة الأنجلو المصربيه

\section{Publisher's Note}

Springer Nature remains neutral with regard to jurisdictional claims in published maps and institutional affiliations. 